ALTRUIS, e-ISSN 2620-5513, p-ISSN 2620-5505, Vol. 1, No. 1, April 2018

Abdimas Altruis: Jurnal Pengabdian Kepada Masyarakat

http://e-journal.usd.ac.id/index.php/ABDIMAS

Universitas Sanata Dharma, Yogyakarta

\title{
Mewujudkan Perajin Gerabah yang Mandiri Melalui Program $I_{b} M$
}

\author{
Rubiyatno $^{1}$, Josephine Wuri ${ }^{2}$, Lisia Apriani ${ }^{3}$ \\ ${ }^{1}$ Program Studi Manajemen Universitas Sanata Dharma Yogyakarta \\ ${ }^{2}$ Program Studi Akuntansi Universitas Sanata Dharma Yogyakarta \\ ${ }^{3}$ Program Studi Akuntansi Universitas Sanata Dharma Yogyakarta \\ email: rubi@usd.ac.id \\ https://doi.org/10.24071/altruis.2018.010102
}

\begin{abstract}
The purpose of this community service is to enhance entrepreneurial motivation, improve understanding of human resource optimization, improve partners' understanding of business plans and also produce business plan documents as business development plans and improve financial management. As a result, innovative product designs have the value of selling by utilizing information technology, understanding and entrepreneurship skills in their fields, enhancing the ability of craftsmen in using the Internet network for expansion of marketing, improving financial management through cash flow, and the ability of partners to operate a financial-based application program a simple computer. Participatory approaches are used for partners to actively participate in all activities from start to finish. After conducting discussion with Partners 1 and 2, we provided the necessary training and mentoring to help overcome the weaknesses of Partners 1 and Partners 2, pottery craftsmen in Panjangrejo Pundong area, Bantul. After completing the program, it can be concluded that Partner 1 and Partner 2 were extremely enthusiastic in this activity due tothe desire to be good at developing their business and all targeted indicators have been achieved, for example, customer identification and availability of production equipment.
\end{abstract}

Keywords: kewirausahaan, manajemen bisnis kecil, teknologi informasi

\section{PENDAHULUAN}

Pusat kerajinan gerabah Panjangrejo terletak di 14 km sebelah selatan Kota Bantul. Nama Panjangreja tenggelam oleh kepopuleran kecamatannya, Pundong. Maka tidak mengherankan apabila Pundong lebih dikenal akan kerajinan gerabahnya. Walaupun tak setenar Kasongan, Desa Panjangrejo menawarkan alam pedesaan yang khas. Hamparan lanskap hijau menguning yang memanjakan mata. Tak salah kemudian pada 2003 kawasan ini ditetapkan sebagai desa wisata. Desa Panjangrejo menghasilkan pelbagai jenis kerajinan gerabah dari tanah liat, seperti maron (tempat air), padasan (tempat wudhu), tungku, dan produk yang telah dikembangkan seperti wine cooler (tempat botol), tempat lilin, kap lampu, nampan, topeng, patung, vas bunga, dan pelbagai souvenir.

Menjadi salah satu sentra gerabah di kawasan Bantul sudah dimulai sejak 1978. Hingga kini manfaatnya sangat dirasakan terutama bagi penyediaan lapangan pekerjaan. Kawasan ini mencapai era keemasan sekira awal 2000. Kala itu ada sekitar178 tenaga kerja yang terserap ke industri ini, masing- masing ke Siti Aji Tri Tunggal, Siti Kencono, dan Sri Puspito yang semuanya terdapat di Desa Panjangrejo.

Gempa bumi yang mengguncang Yogyakarta dan Jawa Tengah pada Mei 2006 memutus sejarah berkembangnya kerajinan di Panjangrejo. Namun bersama Gabungan Kelompok Perajin Panjangrejo Pundong (GKP3), sebanyak 190 pengrajin bahumembahu menata kembali kejayaan gerabah Pundong. Proses recovery dimulai setelah satu tahun gempa.

Seperti membuka lembaran baru, tragedi gempa justru memicu pengrajin Panjangrejo membuat inovasi gerabah, di antaranya adalah keramik cover dan desain abstrak. Keramik cover yang baru dikenal beberapa tahun terakhir ini meninggalkan pakem pendahulunya. Produk seperti guci, vas tinggi, gentong, dan bola, dipoles agar lebih menarik dengan memberi ornamen tambahan. Mereka menggunakan rotan, kulit telur, dan pelepah pisang untuk menambah aksen di permukaan keramik.

Perajin Gerabah di Desa Panjangrejo dalam menghadapi mekanisme pasar yang makin terbuka dan kompetitif, penguasaan pasar merupakan prasyarat untuk meningkatkan daya saing UMKM. Agar dapat menguasai pasar, maka UMKM perlu mendapatkan 
informasi dengan mudah dan cepat, baik informasi mengenai pasar produksi maupun pasar faktorproduksi. Informasi tentang pasar produksi sangat diperlukan untuk memperluas jaringan pemasaran produk yang dihasilkan oleh UMKM.

Informasi pasar produksi atau pasar komoditas yang diperlukan misalnya (1) jenis barang atau produk apa yang dibutuhkan oleh konsumen di daerah tertentu, (2) bagaimana daya beli masyarakat terhadap produk tersebut, (3) berapa harga pasar yang berlaku, (4) selera konsumen pada pasar lokal, regional, maupun internasional. Dengan demikian, UMKM dapat mengantisipasi berbagai kondisi pasar sehingga dalam menjalankan usahanya akan lebih inovatif.

Sedanzgkan informasi pasar faktor produksi juga diperlukan terutama untuk mengetahui: (1) sumber bahan baku yang dibutuhkan, (2) harga bahan baku yang ingin dibeli, (3) dimana dan bagaimana memperoleh modal usaha, (4) di mana mendapatkan tenaga kerja yang professional, (5) tingkat upah atau gaji yang layak untuk pekerja, (6) di mana dapat memperoleh alat-alat atau mesin yang diperlukan (Ishak, 2005).

Untuk itu perlu kiranya bagi perajin di Desa Panjangrejo dilakukan capacity building, proses atau kegiatan memperbaiki kemampuan seseorang, kelompok, organisasi atau sistem untuk mencapai tujuan atau kinerja yang lebih baik (Brown et. al, 2001). Capacity building adalah pembangunan keterampilan (skills) dan kemampuan (capabilities), seperti kepemimpinan, manajemen, keuangan dan pencarian dana, program dan evaluasi, supaya pembangunan organisasi efektif dan berkelanjutan. Ini adalah proses membantu individu atau kelompok untuk mengidentifikasi dan menemukan permasalahan dan menambah wawasan, pengetahuan dan pengalaman yang dibutuhkan untuk memecahkan masalah dan melakukan perubahan. (Campobaso dan Davis, 2001) Capacity building difasilitasi melalui penetapankegiatan bantuan teknik, meliputi pendidikan dan pelatihan, bantuan teknik khusus (specific technical assitance) dan penguatan jaringan.

Prinsip yang perlu diterapkan adalah membangun keberdayaan ekonomi rakyat melalui pengembangan kapasitas (capacity building), mencakup : 1) kelembagaan; 2)pendanaan, 3) pelayanan. Di samping itu masalah internal yang harus dihadapi adalah masalah efisiensi, keterbatasan SDM dan teknologi (Krisnamurthi, 2002).

\section{Mitra 1}

Kelompok perajin gerabah Dusun Gedong Desa Panjangrejo yang berjumlah kurang lebih 10 orang dibawah koordinir bapak Bapak Sunardi merupakan kelompok perajin yang berusaha meningkatkan kemandirian hidup. Perajin sebagai pelaku usaha kecil biasanya sulit untuk bisa bangkit kalau tidak ada yang memberikan pengarahan dan pendampingan yang teratur. Dalam rangka mewujudkan cita-cita meningkatkan usaha perajin Bapak Sunardi telah berusaha membangkitkan para perajin agar mau untuk menerima masukan dan arahan yang sifatnya untuk pengembangan usaha gerabah yang telah dijalani oleh para perajin sejak bertahun tahun. Para perajin umumnya masih menjalani usaha dengan asal jalan tanpa perencanaan bisnis dan manajemen yang memadai. Hal lain adalah sebagian perajin gerabah tersebut menjalani usahanya bukan sebagai satu satunya gantungan hidupnya. Keinginan dan niat Mitra terutama Bapak Sunardi sangat bagus, namun masih perlu dibenahi karena masih memiliki banyak kelemahan yaitu a) dalam bidang desainproduk, b) pembuatan sampel produk, c) motivasi usaha, d) pemasaran, e) pencatatan transaksi dan f) kemampuan terhadap teknologi komputer.

\section{Mitra 2}

Bapak Agus yang beralamat di Dusun Nglorong Desa Panjangrejo merupakan perajin yang memiliki keinginan untuk maju yang sangat tinggi. Produk yang dihasilkan oleh bapak Agus mampu menembus pasar internasional. Bapak Agus selama ini dalam memenuhi permintaan akan produknya, selain memiliki karyawan sendiri juga mengandalkan kurang lebih 4 pemasok yang sangat dipercaya mampu menghasilkan produk yang berkualitas sehingga bernilai jual. Sebenarnya di wilayah sekitarnya terdapat lebih dari 10 perajin yang lain memiliki potensi untuk dikembangkan untuk dapat memenuhi permintaan yang diterima bapak Agus. Bapak Agus memang memiliki kepedulian yang tinggi terhadap pengembangan industri gerabah di Bantul dan khususnya diPanjangrejo. Bapak Agus selama ini sering mengalami kesulitan dalam memenuhi permintaan produk dalam jumlah yang besar, dikarenakan para pemasok bapak Agus memiliki kelemahan a) dalam bidang desain produk, b) pembuatan sampel produk, c) motivasi usaha, d) pemasaran, e) pencatatan transaksi dan f) kemampuan terhadap teknologi komputer baik untuk desain produk, aministrasi keuangan maupun untuk pemasaran.

a. Produksi

Perajin yang menjadi pemasok bapak Agus belum memiliki ragam desain dan contoh/sampel produk yang yang inovatif sehingga memiliki nilai jual yang tinggi. 
b. Pencatatan transaksi keuangan

Pencatatan transaksi belum tertib sehingga ada transaksi yang tidak dicatat, sehingga mengalami kesulitan untk mengetahui keuntungan yang diperoleh dari usahanya.

c. Sumber daya manusia.

Para perajin masih belum memiliki jiwa dan semangat kewirausahaan yang tinggi serta kemampuan manajemen usaha yang sangat rendah.

\section{METODE}

1. Melalui kegiatan IbM ini akan ditawarkan solusi bagi permasalahan-permasalahan yang telah dirumuskan di atas. Pendekatan yang ditawarkan bagi realisasi program IbM ini adalah model pemberdayaan dengan langkah-langkah sebagai berikut : 1) tahap persiapan; 2) tahap assesment; 3) tahap perencanaan alternatif program atau kegiatan; 4) tahap pemformulasian rencana aksi; 5) tahap pelaksanaan (Implementasi) program atau kegiatan; 6) tahap evaluasi; serta 7) tahap terminasi.

2. Pelaksanaan program IbM ini memang dilaksanakan sebagai upaya pemberdayaan kelompok pemuda dalam bidang kewirausahaan melalui kegiatan pelatihan kewirausahaan yang menitikberatkan kepada pengembangan usaha. Metode pelaksanaan program yang akan dilakukan adalah : (1) pelatihan manajemen usaha, (2) Pelatihan produksi khususnya dalam desain, (3) pelatihan administrasi keuangan dan (4) pendampingan. Semua metode ini merupakan satu kesatuan dari program IbM ini.

\section{HASIL DAN PEMBAHASAN}

Program IbM ini dilaksanakan dengan hasil sebagai berikut:

\section{A. Sosalisasi Program IbM kepada Mitra 1 dan 2}

Kegiatan sosialisasi ini didahulu dengan melakukan kunjungan ke mitra 1 dan 2 seminggu sebelumnya untuk melakukan kesepakatan pertemuan. Kegiatan Sosialisasi disepakati dan dilasanakan tanggal 12 Mei 2016, dihadiri oleh mitra 1 dan mitra 2, serta beberapa perajin yang bekerja sama dengan mitra. Dalam pertemuan tersebut disepakati rangkaian kegiatan IbM, yang meliputi : survei keadaan perajin, pelatihan kewirausahaan dan manajemen usaha, pelatihan pembukuan dan menghitung harga pokok produksi dan pelatihan manajemen pemasaran berserta pemanfaatan teknlogi informasi.

Karena dalam pelaksanaan program ini tidak hampir selalu melibatkan para perajin, maka dampak kegiatan tidak hanya dirasakan oleh Mitra 1 dan Mitra
2 saja. Maka sesungguhnya secara langsung dan tidak langsung kegiatan IbM ini akan berdampak luas.

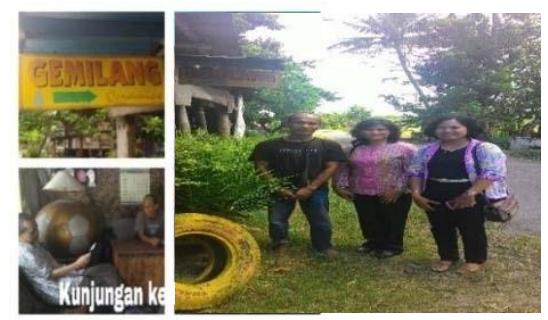

Gambar 1. Sosialisasi

\section{B. Pelatihan kewirausahaan dan manajemen usaha}

Pelatihan ini dilaksanakan secara sederhana pada tanggal 25 Mei 2016 dengan memberikan materi mengenai motivasi jiwa kewirausahaan kepada para perajin, khususnya kepada mitra 1 dan mitra 2.Mereka diharapkan memiliki kesadaran bahwa dengan menjalani usaha sebagai perajin keramik merupakan usaha yang mampu menopang hidupnya di masa depan jika dijalani dengan sungguh sunguh da nada keiginan untuk maju, sehingga dapat menjadi lebih sejahtera apabila dilakukan tidak asal jalan, dengan semangat yang tinggi, dan dikelola secara profesional, dengan melakukan produksi dan pemasaran yang benar.

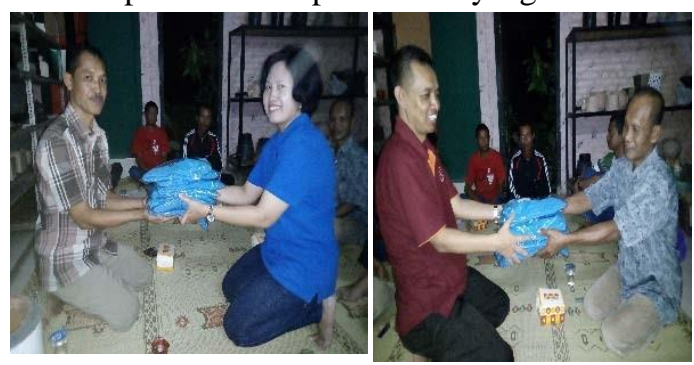

Gambar 2. Pelatihan dan Penyerahana Bantuan

\section{Identifikasi Pelanggan}

Pelanggan yang dimiliki oleh mitra 1 bapak Sunardi sebagian besar adalah trader yang ada di Yogyakarta, salah satunya adalah Nusantara dann Puspasari. Sedangkan mitra 2 yaitu bapak Agus memiliki pelanggan yang dari berbagai kota baik di Jawa Tengah maupun Jawa Timur dan juga dari luar negeri, misalnya dari dari Purworejo, Surabaya dan Kendal. Dari indentifikasi tersebut dapat dilihat bahwa mitra 1 pelanggannya adalah trader yang ada di kota Yogyakarta, sedangkan mitra 2 pelanggannya adalah pedagang souvenir yang ada di wilayah Jateng DIY dan pembeli langsung dari Swedia dan Jerman untuk keramik ukuran besar, dalam kontek inilah anatara mitra 1 dan mitra 2 telah sepakat untuk melakukankolaborasi dengan cara mitra 2 akan memberikan pekerjaan kepada mitra 1. Dalam hal ini diharapkan akan mendapatkan harga yang lebih kompetitif. 

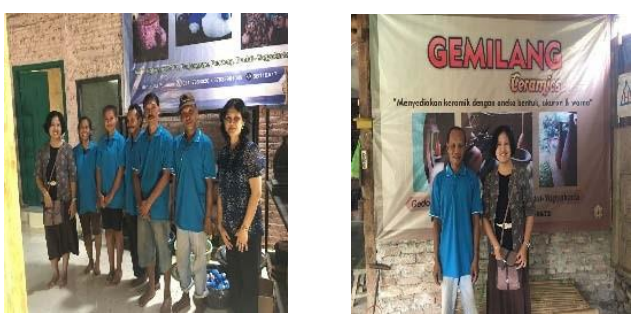

Gambar 3. Kunjungan pendampingan

\section{Desain Pemanfaatan Internet untuk Pemasaran}

Pelaksanaan kegiatan ini merupakan awal dari pemanfaatan internet dengan memanfaatkan blog, adapun alamatnya adalah agusceramics.worpress.com dan gemilangceramic.wordpress.com. Kedua blog tersebut masih dalam tahap pengembangan diharapkan dalam beberapa minggu ke depan sudah lebih baik lagi.

Setelah dilakukan pelatihan pemnafaatan internet untuk pemasaran mitra masih ada keraguan dengan memanfaatkan perdagangan secara online, karena pengalaman masa lalu telah mencoba memakai facebook, ternyata calon pelanggan hanya melihat sampelnya saja, belum tentu melakukan pembelian. Mitra melakukan cara mencari penjual keramik atau pedagang keramik lalu dihubungan dengan memanfaatkan Blackberry masanger, ternyata hal ini membuahkan hasil. Perlu diketahui bahwa mitra 1 hanya melayani keramik dengan ukuran yang besar, sedangkan mitra 2 selain melayani keramik ukuran besar juga melayani keramik ukuran kecil untuk souvenir.

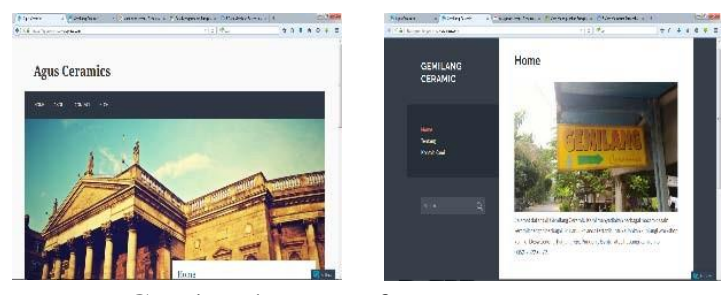

Gambar 4. Pemanfaatan Internet

\section{E. Pelatihan Desain Produk dengan Pemanfaatan Komputer}

Pada pelatihan ini memang dapat dikatakan kurang berhasil selain kemampuan computer mitra masih terbatas, mitra kurang terbiasa dengan software yang dipakai yaitu Corel. Meskipun demikian sasaran dari program ini masih dikatakan berhasil dengan pendampingan oleh tim mira termotivasi membuat sampel hal itu terlihat dengan semakin banyaknya sampel yang terdisplay di show room mitra, apalagi setelah mendapatkan bantuan rak kaca.

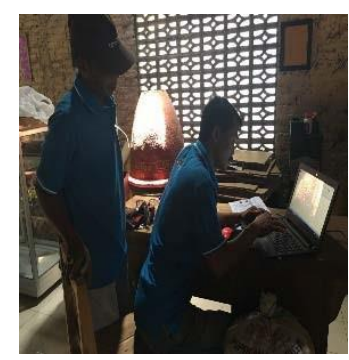

Gambar 5. Pemanfaatan Komputer

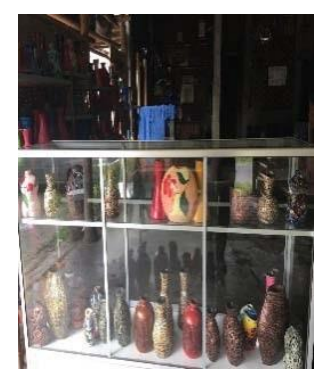

Gambar 6. Display sampel

\section{F. Pelatihan administrasi keuangan}

Pelatihan ini dilakukan pada tahap terakhir dengan harapan dapat mendapatkan data keuangan yang memadai sebagai sarana untuk dipraktekkan dalam latihan. Pada pelatihan ini mitra sangat antusias akan tetapi pada saat mempratekkan ternyata mitra memerlukan pendampingan yang lebih banyak agar dapat memanfaatkan teknologi computer dalam melakukan administrasi keuangan perusahaan. Keberadaan computer sedikit banyak sangat meningkatkan motivasi mitra untuk menjalankan administrasi keuangan usaha secara sederhana, bahkan dalam jangka panjang masih menginginkan untuk diajarkan yang lebih kompleks.

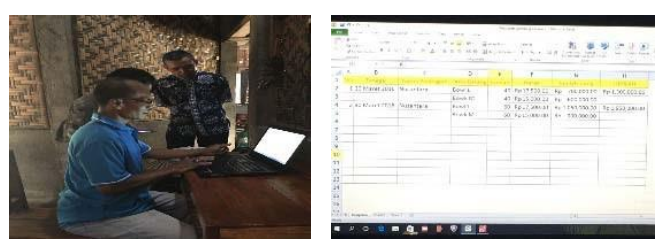

Gambar 7. Pelatihan Administrasi

\section{KESIMPULAN DAN SARAN}

\section{Kesimpulan}

Kesimpulan dari kegiatan yang sudah dilaksanakan selama ini adalah:

1. Mitra baik mitra 1 maupun mitra 2 sangat antusias melaksanakan kegiatan dalam program IbM ini, karena terdorong keinginan untuk menjadi baik dalam mengembangkan usahanya.

2. Seluruh indikator yang ditargetkan sudah tercapai, misalnya dalam hal identifikasi pelanggan serta tersedia pendukung produksi

\section{Saran}

Setelah melaksanakan program kegiatan ini dan melihat indikator keberhasilan yang telah dan masih diupayakan tercapai maka beberapa saran dapat disampaikan sebagai berikut : Program pendampingan sebagai kelanjutan program kegiatan ini masih perlu dilanjutkan agar hal hal yang telah baik dapat dipertahankan bahkan dingkatkan. Misalnya dengan 
selalu memotivasi mitra agar lebih produktif dan kreatif.

\section{DAFTAR PUSTAKA}

Campobasso, L and D Davis, (2001). Reflection on Capacity Building, the California
Wellness Foundation Journal, Volume 2 no. 2. California: Wellness Foundation Ishak, Effendi. (2005). Artikel : Peranan Informasi Bagi Kemajuan UKM. Yogyakarta : Kedaulatan Rakyat.

Krisnamurthi, Bayu. (2002). RUU Keuangan 